\title{
MÚLTIPLAS SUBALTERNIDADES, MÚLTIPLAS RESISTÊNCIAS. REFLEXÕES SOBRE MULHERES, ESCRITA E COLONIALISMO A PARTIR DA ESCRITA DE ALDA ESPÍRITO SANTO
}

MULTIPLE SUBALTERNITIES, MULTIPLE RESISTANCE. REFLECTIONS ON WOMEN, WRITING AND COLONIALISM STARTING FROM THE WRITING OF ALDA ESPÍRITO SANTO

Noemi Alfieri ${ }^{1}$

1 Universidade Nova de Lisboa.

Via Atlântica, Sâo Paulo, n. 39, p. 268-297, set. 2021. doi: 10.11606/va.i39.181176 
Resumo: Este ensaio aborda a produção literária de intelectuais que se opuseram ao colonialismo português em África, reconhecendo o papel ativo que tais produções tiveram na história, os processos culturais e políticos que as influenciaram e suas repercussões. A trajetória da escritora são-tomense Alda Espírito Santo constitui uma oportunidade para pensar como múltiplas opressões (de classe, raça e género) foram experienciadas na época, assim como para repensar a marginalização destas intelectuais em relação aos colegas e companheiros de luta seus contemporâneos. Representa, ainda, um pretexto para pensar os limites da ideia de unificação das lutas que tem permeado algumas construções discursivas.

Palavras-chave: Subalternidade, resistência, Alda Espírito Santo, colonialismo. 
Abstract: This essay addresses the literary production of women intellectuals who opposed Portuguese colonialism in Africa, recognizing the active role that such productions played in history, the cultural and political processes that influenced them and their repercussions. The trajectory of Santomean writer Alda Espírito Santo it's an opportunity to think about how women experienced multiple oppressions (of class, race and gender), as well as to rethink the marginalization of these intellectuals in relation to their contemporary male camrades. Furthermore, it represents an occasion to rethink the limits of the idea of unification of struggles that has permeated some discursive constructions.

Keywords: Subordination, resistance, Alda Espírito Santo, colonialism. 
A opressão à qual as mulheres, sobretudo em territórios coloniais, estiveram sujeitas durante o Estado Novo português estava patente na propaganda feminina e na maneira com que tal propaganda era aplicada às realidades coloniais e, especificamente, às mulheres africanas. A visão estereotipada da mulher veiculada pelo regime salazarista atribuía-lhe papéis e funções bem definidas na perpetuação da vida da pátria, com destaque para o trabalho doméstico e a educação dos "filhos da nação". Essa forma de opressão combinava-se, em territórios coloniais, com a ideia de missão civilizadora: em Angola, foram por exemplo instituídas escolas residenciais para mulheres negras, no intuito de transformá-las em mulheres mais civilizadas, mais bem-comportadas, elevando o seu nível moral (STUKI, 2019, p. 21 e ss.) e fazendo com que elas contribuíssem para a modernização da sociedade e a afirmação e consolidação da família, tal como entendida pelo regime, em África. Essas questões estavam relacionadas com a própria perceção colonial do corpo negro e com a dicotomização, no imaginário ocidental, da mulher africana como símbolo do Eros e do Thanatos: ao mesmo tempo vital (na associação às ideias de sexualidade e fecundidade) e mortífera e antiga (ideias de agressividade e aniquilamento) (BIHAN, 2019, p. 337-361).

A ideia de unificação das lutas que tem permeado algumas narrações pós-coloniais é problemática sob vários aspetos, já que o reduzir a subalternidade de 
género a uma questão de classe ou a uma mais generalizada forma de opressão, gerada pela existência de um regime ditatorial ou de um sistema colonial, é uma forma de negação da subalternidade imposta pelos regimes patriarcais. De forma análoga, reduzir a subalternidade das mulheres não brancas à questão feminina (sem tomar em conta os modos em que a construção social da raça exerce pressão sobre essas últimas) é uma negação da sua subalternidade em relação às mulheres socialmente percebidas como brancas. Longe de ter o intuito de ser divisivo, o reconhecimento das múltiplas subalternidades em que têm insistido as teóricas do feminismo interseccional e as do feminismo decolonial apresenta-se como uma ferramenta útil para reconhecer as várias camadas de permeabilidade das narrativas coloniais, capitalistas e patriarcais. A luta contra a invisibilização das mulheres não brancas, negras, ou do Sul global é assim, para teóricas como Grada Kilomba, Djamila Ribeiro ou Françoise Vergés, como já o foi para Bell Hooks e Angela Davis, a representação da luta total. Isso porque a combinação de questões de raça, género e classe é a que mais contribui para desmascarar a narração discursiva e a opressão geradas pelas permanências coloniais (ou pela colonialidade) e pela lógica capitalista numa escala de opressões e subalternidades múltiplas que tem o seu ápice na violência experienciada pelas mulheres negras. Em resposta aos ar- 
gumentos que veriam nessa visão uma fonte possível de divisão, Françoise Vergés responde:

Certes, des hommes profitent aussi de la division Nord/Sud et d'autres hommes sont mis dans la situation de les entretenir, mais si j'insiste sur le rôle des femmes du Sud global dans cette organisation du monde, c'est pour souligner d'autant plus son caractère révolutionnaire dans la critique du capitalisme racial et de l'hétéropatriarcat. ${ }^{2}$ (VERGÉS, 2019, p. 9)

Sem entrarmos em questões teóricas sobre os vários tipos de feminismos e as distintas ondas do feminismo, parece-me escusado afirmar que, apesar das divergências e de uma recusa comum, por parte dessas autoras, do feminismo neoliberal ou burguês, um tipo de feminismo não invalida o outro. Isso até porque determinado tipo de feminismo anticapitalista, como o de Silvia Federici, tem insistido - pelo menos na última década - exatamente em refletir sobre a demonização da mulher colonizada levada a cabo pelo patriarcado. É nesta ótica de múltiplas invisibilizações, de várias camadas de violências exercidas pelo sistema patriarcal, colonial e do capitalismo racial que entendemos abordar a escrita de autoras africanas como Alda Espírito Santo (mas poderíamos nomear Alda Lara, Manuela Margarido, Noémia de

2 As posições da intelectual francesa são igualmente explicitadas na publicação «Face au féminisme carcéral. Entretien avec Françoise Vergès» in Trou Noir. Voyage dans la dissidence sexuelle, 28/10/2020. Disponível http://trounoir.org/?Face-au-feminisme-carceral-Entretien-avec-Francoise-Verges 
Sousa e Deolinda Rodrigues) que, ao longo dos anos 50 e 60 do século passado, se posicionaram contra o colonialismo português e/ou pela independência política dos seus países e que, apesar de diferenças de percursos, foram intelectuais acomunadas pela recusa do sistema de dominação colonial e que abordaram questões de género. A sua escrita ajuda-nos, assim, a repensar questões do presente, contrariar invisibilidades, imaginar soluções possíveis.

Papel e representação da mulher na propaganda colonial: disparidades raciais e de género

Com a afirmação de que as sociedades coloniais reproduziram as políticas femininas do Estado Novo português, entendo evidenciar a ação direta da propaganda colonial e a irremediável continuidade que houve entre hábitos, estilos de vida, representações e formas mentis que tinham sido frequentemente interiorizadas pelos homens e pelos próprios sujeitos femininos, acabando por ser reproduzidas na organização social e cultural. Entidades associativas como a OMEN (Organização das Mães pela Educação Nacional, fundada em 1936) ou a Mocidade Portuguesa Feminina (MPF, dependente da OMEN) reproduziam a conceção da mulher como reprodutora, guardiã do lar, educadora dos filhos e nacionalista exemplar. Essencialmente, à medida que se reconhecia um papel fundamental à mulher na edificação e na manutenção 
da Nação, ela acabava por ser relegada a um papel de retaguarda que, se comparado ao dos homens, era meramente figurativo. Em várias ocasiões, a figura feminina acabou por ser utilizada pelo Estado Novo como instância legitimadora das políticas governativas e veículo da propaganda nacional ou imperial, como foi o caso do Movimento Nacional Feminino na Guerra colonial (1961-74). Irene Pimentel tem realçado que os dois campos públicos reservados às mulheres que não se limitavam a ser "mães, esposas e irmãs" eram o da assistência e da educação(PIMENTEL, 2000, p.25).

A partir dos anos 50, as mulheres portuguesas foram mobilizadas pelo Estado (e, em alguns casos, mobilizaram-se) na defesa ideológica do Império, utilizando-se, para esse fim, o sistema de ensino, a imprensa e as organizações femininas. Mesmo assim, mesmo em iniciativas oficiais como o Concurso de Literatura Colonial, a participação feminina não foi expressiva desde o ponto de vista numérico, sendo apresentadas a concurso, entre 1926 e 1951, só onze obras de autoria feminina de um total de 243 (SANTO, 2015 , p. 99). No que respeita à sétima arte, já no âmbito do colonialismo português tardio, assistimos, no cinema "de regime", a uma representação da mulher negra $^{3}$ que não se afasta muito daquela que já tinha sido a veiculada por revistas como Portugal Colonial,

3 Ver a este propósito Maria do Carmo Piçarra, «Pele negra ou pele branca: máscara(s) da mulher imaginada pelo cinema colonial», in Observatório, Volume 9, no 2, Lisboa, 2015. 
editada entre 1931 e $1937^{4}$ : desumanizada, racializada e objetificada. À objetificação correspondia, sem saída possível, o silenciamento, sobre o qual tem recentemente refletido - desta vez do ponto de vista da psicologia coletiva - Grada Kilomba, tomando como ponto de partida a máscara forçadamente aplicada para tapar a boca dos escravos:

A máscara suscita, pois, muitas perguntas: porque é que é preciso fechar a boca do sujeito negro? Porque tem ela/ele de ser silenciada/o? 0 que poderia o sujeito negro dizer se a sua boca não fosse selada? E o que teria de escutar o sujeito branco? Há um medo apreensivo de que, se o sujeito colonial falar, o colonizador terá de ouvir. Seria forçada/o a um confronto incómodo com verdades "Outras". Verdades negadas, reprimidas, guardadas como segredos. (KILOMBA, 2019, p. 41)

Os mecanismos de silenciamento histórico frequentemente implicam, como observa a autora, a perpetuação inconsciente de mecanismos de reprodução da subalternidade (neste caso, estou a pensar na racial). Como antecipamos, alguns estudos feministas, especialmente os levados a cabo por teóricas feministas negras, têm destacado como algum feminismo ocidental, focando-se na subalternidade da mulher em relação ao homem, tem posto de parte as

4 Pelo que respeita a representação da mulher na revista, ver Aldina Marques, Isabel Margarida Duarte, Alexandra Guedes Pinto, Catarina Pinho, «A construção da identidade da mulher em revistas do Estado Novo», in Ex æquo, no 39, 2019, p. 71-88. 
questões de raça e classe: se já mencionamos Françoise Vergés, podemos fazer agora referência a Angela Davis e bell hooks ${ }^{5}$. As feministas brancas de classe média, afirmam em suma as autoras, têm a tendência de subestimar - ou ignorar deliberadamente - aspetos que se revelam cruciais na compreensão das disparidades que caracterizam as sociedades modernas. Relativamente à opressão de que as mulheres negras sofrem, apontando ao "feminismo branco" a culpa de se ter focado nas consequências negativas do patriarcado em nível económico, sem realçar devidamente a transversalidade (social, racial e económica) da opressão, bell hooks declara:

Black leaders, male and female, have been unwilling to acknowledge black male sexist oppression of black women because they do not want to acknowledge that racism is not the only oppressive force in our lives. Nor do they wish to complicate efforts to resist racism by acknowledging that black men can be victimized by racism but at the same time act as sexist oppressors of black women. (HOOKS, 1981, p.68)

A múltipla opressão e subalternidade que as palavras de hooks denunciam é relevante para a compreensão não só dos poemas e das reflexões de mulheres que viveram o jogo colonial, mas também, lembramos mais uma vez, para enquadrar o distinto peso que

5 Estou a pensar, concretamente, nas observações de Angela Davis em Women, race and class e de bell hooks em Ain't I a woman. 
tais estruturas coloniais tinham na vida das mulheres brancas e negras, tal como o nível de interiorização destas mesmas estruturas no pensamento e nas obras elaboradas por estas mulheres.

\section{Escritoras africanas: uma história de invisibilização}

A literatura produzida nos anos 50 e 60 do século passado, em países sob o domínio colonial português, tal como o era São Tomé e Príncipe, foi uma literatura geralmente engajada, profundamente preocupada com a evolução das sociedades em que se inseria, com o contexto da guerrilha, as estruturas coloniais e o possível desenvolvimento dos conflitos que, cada vez mais, se iam espalhando pelo continente africano.

Nas reproduções posteriores às independências africanas, e em função das construções das narrativas nacionais que caracterizaram os estados independentes, houve uma compreensível tendência para a hipervalorização da literatura marcadamente militante, de combate e de revolta. Assim, obras de autoras cuja contribuição foi fundamental para a consciencialização dos próprios intelectuais que se consagraram como autores nacionais moçambicanos, angolanos ou cabo-verdianos, por exemplo, passaram para um plano secundário, se comparadas com o que foi atribuído aos colegas e camaradas homens que as sucederam ou que foram seus contemporâne- 
os. Isso aconteceu tanto dentro do espaço nacional de que as escritoras eram oriundas como fora dele e até fora do espaço de língua portuguesa. Basta pensar, em relação à divulgação em nível internacional, na African Writers Series, publicada a partir de 1962, com o objetivo de divulgar obras literárias de autores africanos ao grande público. As literaturas africanas em língua portuguesa foram claramente sub-representadas (não podemos esquecer que o público alvo era fundamentalmente de língua inglesa), tendo-se realizado, contudo, a publicação de quatro grandes clássicos da escrita africana daqueles anos: Luís Bernardo Honwana com Nós matámos o cão tinhoso, Amílcar Cabral com Unidade e Luta, Luandino Vieira com Luuanda e Pepetela com Mayombe. A ausência de literatura produzida por mulheres, naquela altura, tal como a de Alda Lara, Noémia de Sousa, Manuela Margarido ou Lília da Fonseca na prosa, é indicativa das exclusões que foram produzidas e reproduzidas, mesmo sucessivamente às independências políticas, no âmbito da literatura feminina.

Como evidenciado por Rodrigues e Sheldon (2010), muitas das mulheres que escreveram em revistas, jornais e volumes nas ex-colónias portuguesas estavam diretamente envolvidas na luta anticolonial, fazendo parte das elites e reproduzindo visões que ainda se ressentiam da influência colonial, ocupando o corpo feminino um papel de relevo: 
In both Cape Verde and Mozambique, women's writings have denounced colonial oppression and embraced a newly gained national freedom. Similarly, in both countries (and elsewhere in Lusophone Africa) it is evident that women were engaged with the revolutionary cause either through straightforward party politics or discursively, as female bodies became metaphors for the newly independent nations. (RODRIGUES; SHELDON, 2010, p. 81)

Muitas das mulheres escritora,s acima mencionadas, frequentaram e foram, como vimos, membros ativos da Casa dos Estudantes do Império (CEI), como sublinhado por Inocência Mata, "essas poetisas participaram da utopia da nação"(MATA, 2007, p. 424). Se a CEI e as suas ligações tanto com a Présence Africaine como outros movimentos literários africanos foi fundamental, vimos que a "Casa da tia Andreza", na Rua Actor Vale $\mathrm{n}^{\circ}$ 37, em Lisboa, também foi um lugar de agregação fundamental. Foi o endereço da sede do Centro de Estudos Africanos, cujo secretariado era assegurado por Noémia de Sousa (MATA, 2015, p. 33): a tia Andreza era a tia de Alda Espírito Santo, poetisa são-tomense.

Mesmo em obras coletivas de orientação anticolonial, como o boletim Mensagem e a Colecção de Autores Ultramarinos da CEI, a presença de obras escritas por mulheres nestas publicações, de forma análoga ao que aconteceu nas publicações coloniais das décadas anteriores e de acordo com uma geral tendência da época, revela-se numericamente minoritária 
se comparada com a dos homens: dos 152 poemas, contos e ensaios que Ana Maria Martinho listou como pertencentes aos fascículos da CEI, publicados entre 1948 e 1964, só 10 textos, na maioria poemas, foram escritos por mulheres: Alda Lara, Alda Espírito Santo, Manuela Margarido e Noémia de Sousa (MARTINHO, 2015). Em Novos pactos, outras ficções: ensaios sobre literaturas afro-luso-brasileiras, Laura Cavalcante Padilha evidenciou que, numa obra de referência como foi No Reino de Caliban, de Manuel Ferreira:

a poesia angolana feminina começa a surgir na década de 50 , fato este confirmado também com respeito a Cabo Verde onde, em 36 poetas, só há uma mulher. No caso de Angola, há 6, para 53, enquanto em São Tomé e Príncipe, para sete há duas e nenhuma na Guiné-Bissau, onde, aliás, só se regista o nome de um poeta. (PADILHA, 2002, p. 265)

Alda Espírito Santo e outras mulheres e intelectuais conseguiram rapidamente, graças também à colaboração de Amílcar Cabral, constituir uma rede que se concretizava em encontros presenciais, troca de correspondência e viagens: entre elas Maria Helena Vilhena Rodrigues (primeira mulher de Cabral), Noémia de Sousa e Rute Neto. Sempre através do líder do PAIGC, concretizaram-se os contactos com Deolinda Rodrigues, que passaram da forma epistolar a encontros pessoais em Angola, em 1956 e 1958. As viagens a Paris, realizadas pouco depois do Processo dos '50 
com o objetivo de levar comunicados e informações sobre a situação colonial em Angola, permitiram, para além disso, que Espírito Santo desenvolvesse uma amizade com a realizadora Sarah Maldoror, mulher de Mário Pinto de Andrade e conhecida pelos seus filmes anticoloniais, entre o quais Monangambé (1969) e Sambizanga (1972) .

Redes intelectuais, resistência, feminismo: 0 legado de Alda Espírito Santo

Alda Espírito Santo foi uma intelectual e poetisa paradigmática do seu tempo: o seu género não impediu a sua afirmação enquanto personalidade fulcral no ambiente literário, cultural e político dos movimentos de libertação. 0 facto de ela também ser professora primária (elemento, este, realçado em várias ocasiões nos processos PIDE em seu nome), o seu empenho ativo no esforço de mudança da sociedade, contribuiu para que ela se tornasse um exemplo para as mulheres africanas e portuguesas ${ }^{7}$ : negra, bem sucedida, culta, inserida com sucesso no panorama da

6 Para além de ter fundado em Paris a companhia teatral Les Griots (1956), Sarah Maldoror foi assistente de realização no célebre filme A batalha de Argel, de Gillio Pontecorvo, produção ítalo-francesa, de 1965.

7 Destacamos, como representativo da influência de Alda Espírito Santo e de outras escritoras negras da época: Cristina Roldão, «Feminismo negro em Portugal: falta contar-nos», in Público, 18 de Janeiro de 2019. Disponível https://www.publico. pt/2019/01/18/culturaipsilon/noticia/feminismo-negro-portugal-falta-contarnos-1857501 
militância anticolonialista e antifascista e na luta feminista e antirracista, Alda Espírito Santo representava a subversão de padrões culturais e políticos profundamente radicados na sociedade colonial. 0 polo que a casa da Tia Andreza constituiu, para além de ser alvo de escutas telefónicas e de investigações e rusgas da PIDE, parece ter representado para o regime português uma espécie de arquétipo das redes internacionais de oposição ao jogo colonial. 0 que talvez nos interesse mais ainda, porém, é que ele também serviu de protótipo para certo modelo de coesão cultural que, aos poucos, se ia consolidando nos intelectuais africanos de passagem por Portugal ou no exílio.

Para além das mais óbvias questões de militância e luta ou de difusão da causa anticolonial junto de organizações terceiro-mundistas sediadas na Europa e dos seus órgãos de comunicação e imprensa, o material que circulava na Casa e que foi apreendido pela PIDE diz-nos que a escrita literária, nomeadamente a poética, funcionava, neste contexto, tanto como ferramenta de difusão de certas ideias como era, ela própria, o produto e um testemunho concreto de que novas narrativas iam sendo criadas e já estavam, em certa medida, afirmadas, pois eram reproduzidas fora do contexto da luta anticolonial em sentido estrito: exemplo disso foi a difusão de que gozaram no âmbito de redes de solidariedade de cariz católico ou internacionalista. Estou a pensar, por exemplo, no caso do jornal francês Croissance des jeunes nations, edi- 
tado por Georges Hourdin a partir de 1961, em que foram publicadas, ao lado de extensos artigos sobre a situação das colónias portuguesas, também poemas traduzidos de Alda Espírito Santo.

A poetisa superou as estigmatizações da mulher na sociedade do Estado $\mathrm{Novo}^{8}$, ultrapassando, ao mesmo tempo, as bem mais profundas estigmatizações da sociedade colonial exercidas sobre as mulheres negras. Não deixando de dedicar-se à questão feminina, Alda Espírito Santo foi talvez a autora da época que melhor conjugou a questão de género com a resistência anticolonial, a ligação ancestral à terra com a reivindicação a algum cosmopolitismo enquanto afirmação de humanidade. Assim, no mesmo volume, publicado em França, em que se dava destaque aos discursos de Agostinho Neto e Amílcar Cabral, publicava-se em tradução francesa um poema de Alda Espírito Santo, dedicado ao massacre de Batepá: Oú sont-ils les hommes chassés par ce vent de folie?: «hommes du cinq février/ hommes tombés dans l' étuve de la mort/ implorant la pitié/ urlant pour la vie salve,/morts sans air et sans eau,/ils se lèvent tous/ hors de la fosse commune/ et, debout, em chœur de justice/ crient

8 A escrita feminina foi, nessa época, a concretização da ocupação de um lugar predestinado ao masculino na narração cultural do Estado Novo. Como sublinha Vanda Gorjão, em $\mathrm{Mu}$ Iheres em tempos sombrios - oposição feminina ao Estado Novo, a Escola salazarista previa uma "educação especificadamente feminina"(GORJÃO, 2002, p. 83), tendo a percentagem de alunas universitárias aumentado na década de 60. 
vengeance... ${ }^{9} » .0$ poema, para além do potencial de difusão que tinha fora de Portugal e do seu espaço colonial, não se limitava à denúncia do massacre e da injustiça, abrindo de facto o campo à inevitável reação à violência, como reflete o apelo à unidade do poema de três versos Aos combatentes da liberdade: "Irmãos do mundo, nós somos guerrilheiros/ Das ilhas do mar sem fim/ A força da unidade é nossa metralhadora" (SANTO, 1978, p. 107). Não era a primeira vez que a professora são-tomense se dedicava ao massacre: a famosa carta escrita pelo seu punho, dactilografada e sem data, consta do processo PIDE de Alda Espírito Santo, no ANTT, e das anotações de Lúcio Lara sobre o MPLA, recolhidas na obra documental Um amplo movimento (2017). A carta, presumivelmente enviada para Lisboa, visava pôr os amigos e camaradas ao corrente dos acontecimentos e da repressão criminosa dos protestos, cuja brutalidade se manifestou, segundo o testemunho da autora, a partir do quarto dia de sublevação: “Quarenta e sete indivíduos são metidos numa cela cuja cubagem não permite a respiração normal desses homens, tendo apenas uma janelita insuficiente para se poder respirar eficientemente", ou ainda, "Os homens gritam, pedem água, imploram,

9 Alda Espírito Santo, «Oú sont-ils les hommes chassés par ce vent de folie?», in Croissance des Jeunes nations, no 103, 1970. Contido em ANTT/PT/PIDE-DGS/CI (2), Reg. 4293, folha 193 e seguintes. Este número incluiu o dossier do mês "Une guerre colonial oubliée. L'Afrique contre le Portugal”, com artigos sobre a situação das várias colónias, com particular atenção para com a intensificação dos interesses económicos ocidentais e sul-africanos no espaço colonial a partir de 1960. 
mas perto de 30 indivíduos morrem asfixiados. Os sobreviventes são unânimes em se referirem ao facto e nomes deles surgem" (AAVV, 2017, p. 504-507).

Tal descrição não faz mais do que confirmar as brutais práticas repressivas que o estado português exercia nas prisões das suas colónias africanas. A situação acima descrita não deixa de lembrar as pinturas de Malangatana, que retratavam a Cadeia PIDE da Machava (Moçambique), os relatos de José Craveirinha e a referência à Cela 1 (1980) ou os episódios dos diários da prisão de Luandino Vieira.

Ainda com o propósito de realçar o impacto que a obra de Espírito Santo tinha não só em nível de resistência anticolonial e da representação da outra face do conflito, mas também em questões explicitamente de género, citamos "Voz negra das Américas", poema dedicado a Angela Davis, ou ainda, o dedicado à amiga Deolinda Rodrigues, já depois da sua morte ${ }^{10}$. Não se podendo reduzir a um plano de intervencionismo literário, o da autora são-tomense teve, pelo contrário, o mérito de colaborar com a fortificação de uma rede de contactos de resistência antifascista e anticolonial, dinamizando a já mencionada Casa da Tia Andreza (esta última chegou a ser interrogada várias vezes pela PIDE), centro de reunião,

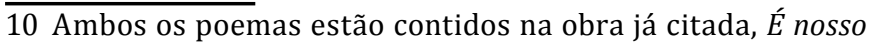
o solo sagrado da terra, respetivamente nas páginas 111 e 113, evocando o exemplo que a luta destas duas mulheres representou para todas as mulheres africanas que ainda viviam num sistema de opressão. 
de circulação e discussão de textos dos movimentos. Para além de comunicados do Comité de Libertação de São Tomé e Príncipe, a PIDE apreendia na casa recortes de artigos e jornais da imprensa internacional (sobretudo em língua inglesa e francesa), que tratavam a questão da violência colonial, da guerra e do ocaso do imperialismo português em África.

Outra questão relevante é a da origem da oposição entre razão e instinto, ou entre mente e corpo, que caracterizou a teoria luso-tropical, mas que se insere, ao mesmo tempo, no mais amplo processo de afirmação do capitalismo na Europa e no mundo ocidental. Retomando o tema da eterna luta entre Próspero e Calibã, Silvia Federici observava, retomando Weber e Marx, que a batalha contra o corpo sempre caracterizou a burguesia na fase da afirmação da lógica capitalista. A necessidade de sujeitar os corpos (todos eles, nomeadamente os dos trabalhadores) às lógicas de produção, e sucessivamente de acumulação, tem-se refletido, para Federici, numa progressiva destruição do conceito de corpo como depositário de poderes "mágicos", que caracterizou a Idade Média. Isso foi necessário porque:

Come la terra, il corpo doveva essere coltivato e anzitutto spezzato perché rilasciasse i suoi tesori nascosti. Esso infatti è condizione dell'esistenza della forza-lavoro, ma ne è anche il limite, in quanto è il primo elemento di resistenza alla sua erogazione. Non bastava quindi stabilire che il corpo in sé non aveva alcun va- 
lore: il corpo doveva morire perché potesse esistere la forza-lavoro. ${ }^{11}$

A necessidade de criar o corpo-máquina implicava, sem possibilidade alguma de fuga, a destruição de todo um sistema de crenças e práticas dos sujeitos pré-capitalistas, o que aconteceu até ao século XIII, tendo a teoria cartesiana contribuído para a consolidação da ideia de relação hierárquica entre corpo e mente. As questões de que Alda Espírito Santo se ocupou não se limitaram, contudo, à condição de exploração da mulher na sua terra e à libertação do povo são-tomense. Em material manuscrito, apreendido pela PIDE em ocasião das buscas efetuadas na casa da tia, verifica-se que a escritora se preocupava com questões como a da condição dos negros portugueses (e com o diálogo com os brancos sobre o que é que significava ser negro português) e com questões como o divórcio como direito humano, assunto sobre o qual escreveu um extenso ensaio. Confirmamos também, a partir dessa correspondência, que a escritora era um ponto de referência crucial na troca delas, fazendo por exemplo de mediadora entre as trocas de carta de Noémia de Sousa e de Viriato da Cruz, recebendo convites literários para participação em antologias de Lília da Fonseca, trocando regular-

11 Silvia Federici, Calibano e la strega: Le donne, il corpo e l'accumulazione straordinaria, Mimesis, Milano, 2015, p. 274. A versão original em inglês, Caliban and the Witch: Women, The Body and Primitive Accumulation, é de 2004. 
mente correspondência com Amílcar Cabral e Alfredo Margarido e difundindo, igualmente, cópias de Faúlha - Órgão da revolução africana.

Percebemos, assim, quão relevante foi a personalidade de Alda Espírito Santo e o que ela representou: a possibilidade de conceber o desmoronamento de um sistema de opressão patriarcal milenar, reproduzido em métodos educativos, na representação masculina das capacidades (ou da inépcia) intelectuais das jovens mulheres e, ainda, na superação de limitações materiais na gestão e no desenvolvimento da carga doméstica que pesava às mulheres. Reconhecemos, apesar disso, que ao abordarmos a questão de género no contexto colonial, estamos, simultaneamente, a pôr em xeque a narração da noção de homogeneidade que Allman, Nakanyke e Musisi definiram como "homogeneous 'African women's experience'" (NAKANYKE; GEIGER MUSISI, 2002, p. 4). A constatação da múltipla opressão que as mulheres africanas enfrentavam não deve levar-nos a cair na armadilha da reprodução (se bem que para os mais nobres propósitos) dos próprios estereótipos coloniais. É importante ter em devida consideração, por exemplo, que a representação - literária ou histórica - que se fez, em nível do imaginário resistente, das mulheres africanas em contextos coloniais relacionou-se, como não podia deixar de ser, com as violências sobre elas exercidas e com a luta armada e a guerrilha. As necessidades (emocionais, práticas, sociais ou cultu- 
rais) que essas mesmas mulheres visavam satisfazer na altura em que eram produtoras ativas de cultura e de literatura no sentido mais amplo do termo não deixaram, contudo, de ter um papel na formação das consciências nacionais. É quase supérfluo esclarecer, assim, que a condição das guerrilheiras rurais pouco ou nada tinha a ver com a de outras guerrilheiras pertencentes às elites coloniais ou a de escritoras que se encontravam em Lisboa a frequentar cursos superiores. A exaltação da estética da guerrilha ${ }^{12}$, a mobilização das mulheres e as considerações sobre a libertação feminina por líderes anticoloniais como Amílcar Cabral ou Samora Machel geraram expectativas sobre a possibilidade de libertação efetiva das mulheres nas sociedades pós-coloniais ${ }^{13}$. Não há dúvida, de facto, de que as causas anticoloniais estivessem

12 Pelo que respeita a representação visual da guerrilha, retratos de mulheres guerrilheiras e de mulheres nas campanhas de alfabetização em Angola estão contidos em Augusta Conchiglia, Agostinho Neto, da guerrilha aos primeiros anos da independência. Luanda: Fundação Agostinho Neto, 2019.

13 Cito, a este propósito, o texto de Tanya Lions: "Guinea-Bissau's revolutionary leader, Amílcar Cabral, argued that a revolution would not be complete without a transformation in the social roles of both men and women, and that women had to fight for and earn equality with men. Samora Machel, the late president of Mozambique, argued that "[t]he liberation of women is a fundamental necessity for the revolution, the guarantee of its continuity and the precondition for its victory." Influenced by the socialist revolutionary successes in Mozambique and Guinea-Bissau, Robert Mugabe, the president of the Zimbabwe African National Union (ZANU), explained that his organization had "learned through the liberation struggle that success and power are possible when men and women are united as equals." Tanya Lyons, "Guerrilla Girls and Women in the Zimbabwean National Liberation Struggle», (LYONS, s.d., p. 305-326). 
comprometidas, em nível ideológico, com a causa da libertação da mulher. Tal preocupação foi manifesta, evidentemente, nos discursos, militantes antes e oficiais depois, de vários líderes no continente. Talvez associações mais comuns, neste sentido, possam ser as posições de Thomas Sankara sobre a libertação da mulher nos anos 80 (também no sentido das de Cabral e Machel), em que o primeiro presidente do Burkina Faso, dando continuidade à tradição pan-africanista, afirmava que nenhuma libertação social concreta era possível sem a libertação da mulher ${ }^{14}$. Como evidenciado por Tanya Lyons, contudo, essa ideia de libertação da mulher era frequentemente associada à ideia de inserção da mulher nos processos de produção, na própria guerrilha ou, de uma forma mais geral, na sua alfabetização. Em muitos casos, assistimos à criação de organizações e associações femininas e de revistas femininas, como foi o caso da AWA - La revue de la femme noire, fundada no Senegal (antiga AOF), em $1954^{15}$. Se é inegável que estas conceções rompiam com a representação e as lógicas fascistas e coloniais, libertando a mulher da prisão doméstica e resgatando-a da ideia de inação, também temos de reconhe-

14 Sobre o assunto ver Thomas Sankara, L'émancipation des femmes et la lutte de libération de l'Afrique. New York: Pathfinder, 2001..

15 A revista, impressa em Dakar, ocupava-se de poesia, política, questões quotidianas, etc. Foi publicada sobretudo entre $1964 \mathrm{e}$ 65, com um número em 1966, dois números em 1972 e dois números em 1973. Ela está disponível integralmente, em formato digital, no link: https://www.awamagazine.org/magazine-index/ e é mencionada em Martine Reid (org), Ivi, p, 502 -503. 
cer a disparidade de papéis atribuídos às mulheres na guerrilha, como Deolinda Rodrigues, intelectual e guerrilheira angolana, testemunhou no seu Diário.

No que respeita especificamente à representação da condição feminina, a escritora são-tomense focava-se na dupla subalternidade da mulher africana, invocando, ao mesmo tempo, uma irmandade entre os povos e todas as mulheres do mundo ${ }^{16}$ :

Situando-nos todos do mesmo lado da canoa, a mulher do mundo, a mulher africana, minha irmã, parte integrante dum todo que é ser social, uma longa marcha, mais longa ainda pelas instituições que remontam às narrações bíblicas, tem de brandir a espada pela emancipação dos povos, e, portanto, pela sua afirmação na luta pelo progresso, pelo grande passo que romperá as barreiras de todas as colonizações. A mulher africana duplamente colonizada, escrava doméstica, serva da colonização, tem uma missão secular a desempenhar na etapa da libertação. ${ }^{17}$

Nos poemas escritos na década de 50 , representava-se assim a condição do trabalho doméstico, aliado ao silenciamento das mulheres negras, como em "Avó Mariana":

Avó Mariana chegou

e sentou-se à porta da sanzala

16 A reflexão de Alda Espírito Santo é útil também para compreendermos as críticas que Grada Kilomba avança ao conceito de sororidade não problematizado e não contextualizado, como estratégia do feminismo branco e ocidental para evitar a difícil discussão sobre racismo e múltiplas opressões.

17 Alda Espírito Santo, Ivi, p. 16. 
e pitou seu jessu lavando, lavando numa barreira de silêncio. (IVI, p. 16) ${ }^{18}$

Lavadeira, levada para a sanzala, passará a sua vida trabalhando até constatar a impossibilidade de, já velha, rever a sua terra, quase sem saber de onde veio: "Onde é terra di gente?/Velha vem, não volta mais...." À resignação da avó Mariana, contrapõe-se à invocação à irmandade vinda da voz da poetisa, que em "Às mulheres da minha terra" constata o sofrimento de mulheres forçadas a viverem na pobreza, na fome do acompanhamento a ser comido sem peixe:

"O dinheiro não chega

Para vencer a nossa fome

Dos nossos filhos

Sem trabalho

Engolindo a banana sem peixe

De muitos dias de penúria"

A força das mulheres negras, vítimas de opressão, vem da comunidade, constituindo o horizonte de libertação tão desejado:

Amigas, as nossas mãos juntas,

As nossas mãos negras

Prendendo os nossos sonhos estéreis

Varrendo com fúria

Com a fúria das nossas "palayés»

Das nossas feiras,

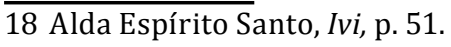


As coisas más da nossa vida.

As palayés são-tomenses, como as quitandeiras (ou zungueiras) angolanas ou outras vendedoras ambulantes africanas, acabam por representar a própria luta: a sua subalternidade é racial, de classe e de género. Nas suas lembranças, a escritora afirma que as vendedoras de rua eram discriminadas por falarem na sua língua materna com as senhoras portuguesas, que responderiam: "Não me fales nessa língua de cão!”, representando a ideia de assimilação, por muitos interiorizadas, de que "o falar português é que permitia o acesso à cultura e à civilização ${ }^{19 " . ~}$. Optando por versos sintéticos e realistas, que tornassem a realidade das mulheres são-tomenses compreensível para todos os falantes de língua portuguesa, Alda Espírito Santos optou, na redação destes poemas, por uma linguagem simples e direta. A poetisa, fugindo de descrições acessórias, recusava amenizar e embelezar poeticamente a crueza da opressão colonial e das suas consequências: se as mulheres são-tomenses eram obrigadas, pela sua condição, a engolirem banana sem peixe, os leitores tinham a obrigação de, e o direito a, refletirem sobre a opressão patriarcal, a pobreza e o colonialismo que as oprimiam.

19 Alda Espírito Santo, Ivi, p. 75. 


\section{Referências}

AAVV, Um amplo movimento, Itinerário do MPLA através de documentos e anotações de Lúcio Lara. $3^{\text {a }}$ ed. revista e aumentada. Luanda: Associação Tchiweka de Documentação (ATD), 2017.

ALLMAN, Jean, GEIGER, Susan, MUSISI, Nakanyke (org). Women in African colonial histories. Bloomington: Indiana University Press, 2002.

BIHAN, Yann L. Catégoriser les femmes africaines en régime colonial. Eros et Thanatos désunis. In BOETSCH, Gilles Boetsch, BANCEL, Nicolas, (org). Sexualités, identités \& corps colonisés. XVe siècle - XXIe siècle. Paris: CNRS Éditions, 2019.

CONCHIGLIA, Augusta. Agostinho Neto, da guerrilha aos primeiros anos da independência. Luanda: Fundação Agostinho Neto, 2019.

DAVIS, ANGELA. Women, race and class. New York: Random House, 1981.

GORJÃO, Vanda. Mulheres em tempos sombrios - oposição feminina ao Estado Novo. Lisboa: ICS, 2002.

HOOKS, bell. Ain' t I a Woman. Boston: South End Press, 1981.

CRAVEIRINHA, José. Cela 1. Lisboa: Edições 70, 1980. KILOMBA, Grada. Memórias da Plantação. Episódios de racismo quotidiano. Lisboa: Orfeu Negro, 2019.

LYONS, Tanya. Guerrilla Girls and Women in the Zimbabwean National Liberation Struggle. In GAIGER, Susan; MUSISI, Nakanyke (orgs.). Women in African Colonial Histories: An Introduction. Bloomington; Chesham: University Press, 2002. p. 305 - 326.

MARQUES, Aldina; DUARTE, Isabel Margarida; PINTO, Alexandra Guedes; PINHO, Catarina. A construção da identidade da Mulher em revistas do Estado Novo. Ex Aequo Revista da Associação Portuguesa de Estudos Sobre As Mulheres, [S.L.], n. 39, p. 71-88, 15 jun. 2019. Associacao 
Portuguesa de Estudos sobre as Mulheres - APEM. http:// dx.doi.org/10.22355/exaequo.2019.39.05.

MARTINHO, Ana Maria. Reflexões em torno dos contributos literários na Mensagem da Casa dos Estudantes do Império. In Mensagem, 1944 - 1994. Lisboa: UCCLA, 2015. MATA, Inocência. Mulheres de África no espaço da escrita: a inscrição da mulher na sua diferença. In MATS, Inocência; PADILHA, Laura Cavalcante (orgs.). A mulher em África. Vozes de uma margem sempre presente. Lisboa: Edições Colibri, 2007.

MATA, Inocência. A Casa dos Estudantes do Império e o lugar da literatura na consciencialização política. Lisboa: UCCLA, 2015.

PADILHA, Laura Cavalcante. Novos pactos, outras ficções: ensaios sobre literaturas afro-luso-brasileiras. Porto Alegre: Edipucrs, 2002.

PIÇARRA, Maria do Carmo. Pele negra ou pele branca: máscara(s) da mulher imaginada pelo cinema colonial. Observatório, Lisboa, v. 9, no 2, p. 173-187, 2015.

PIMENTEL, Irene Flunser. História das organizações femininas no Estado Novo. Lisboa: Círculo dos Leitores, 2000.

RODRIGUES, Isabel Fêo P. B. Rodrigues, SHELDON, Kathleen. Cape Verdean and Mozambican Women's Literature: Liberating the National and Seizing the intimate. African Studies Review, v. 53, n. 3, p. 77-99, dez. 2010.

ROLDÃO, Cristina. Feminismo negro em Portugal: falta contar-nos. falta contar-nos. 2019. 18 jan. 2019. Disponível em: https://www.publico.pt/2019/01/18/culturaipsilon/noticia/feminismo-negro-portugal-falta-contarnos-1857501. Acesso em: 20 jan. 2020.

SANKARA, Thomas. L'émancipation des femmes et la lutte de libération de l'Afrique. New York: Pathfinder, 2001. SANTO, Alda Espírito. Aos combatentes da liberdade. in SANTO, Alda Espírito. É nosso o solo sagrado da terra. Lisboa: Ulmeiro, 1978. 
SANTO, Alda Espírito. Carta de Alda Espírito Santo sobre os massacres de São Tomé. In Um amplo movimento, V. I (até Fev. 1961), págs 504- 507.

SANTO, Alda Espírito. Oú sont-ils les hommes chassés par ce vent de folie? In Croissance des Jeunes nations, $\mathrm{n}^{\mathrm{o}}$ 103, 1970, Contido em ANTT/PT/PIDE-DGS/CI (2), Reg 4293, folha 193 e seguintes.

SANTO, Sílvia Espírito. Representações femininas do Império na Primeira Metade do Século XX. in Faces de Eva. Estudos sobre a mulher, Lisboa: Edições Colibri; Universidade Nova de Lisboa, n. 34, p. 89-104, 2015.

STUKI, Andres. Violence and Gender in Africa's Iberian Colonies Feminizing the Portuguese and Spanish Empire, 1950s-1970s. Cambridge: Palgrave Mac Millan, 2019. VERGÉS, Françoise. Un féminisme décolonial. Paris: La fabrique éditions, 2019. 